Article

\title{
The Benefit of Failure: On the Development of Ostrava's Culture
}

\author{
Jan Suchacek
}

Department of Regional and Environmental Economics, Faculty of Economics, VSB-Technical University of Ostrava, 17. listopadu 15/2172, 70833 Ostrava, Czech Republic; jan.suchacek@vsb.cz; Tel.: +42-059-732-2229

Received: 10 April 2019; Accepted: 26 April 2019; Published: 6 May 2019

\begin{abstract}
Peculiar cultures are symptomatic for areas of traditional industry. The purpose of this paper is to analyze and evaluate cultural and creative industries in Ostrava, the third largest town of the country that at the same time constitutes a typical representative of old industrial urban fabrics in the Czech Republic. Special attention will be devoted to the emerging cultural clusters that appear to be indispensable in terms of sustainable cultural management. Unique qualities of Ostrava's culture culminated in 2009, when the town decided to stand for the prestigious title of the European Capital of Culture. Finally, Ostrava did not succeed, nonetheless the contest vivified the discourse on Ostrava's culture and a distinctive potential for the creation of cultural clusters was revealed. Semi-structured interviews accomplished with relevant actors of the town's culture facilitated contextual interpretation of the role of cultural and creative industries as well as mapping the potential cultural clusters in the town. The research question posed in this article is as follows: do development effects formed by the concentration of creative and cultural industries in Ostrava exist? It turned out that the paths towards cultural management sustainability can differ substantially from recipes, which are well-proven in leading developed territories. The results of our analysis confirmed some developmental effects evoked by the concentration of cultural industries and cultural clusters in Ostrava can be identified, but genuine qualitative transformation towards a more cultural and sustainable milieu in Ostrava undoubtedly requires more time.
\end{abstract}

Keywords: management of culture; sustainability; old industrial areas; post-transformation areas; Ostrava

\section{Introduction}

Creative and cultural industries have become buzzwords in the realm of territorial economies. This concerns both theoretical and practical spheres as both above types of industries-or more precisely economic branches-are deemed to be the new opportunities to facilitate development in territories of various scales and ranks [1-3].

New strategies related to territorial competitiveness are typically not devoid of cultural and creative industries. This applies mainly to leading countries, regions and cities. In the contemporary turbulent context, economies have been exposed to innumerable risks that can endanger the path and pattern of their economic sustainability, as well as social and environmental sustainability. Naturally, apart from traditional industries, their cultural and creative peers are jeopardized as well.

In this context, a special position is occupied by cultural clusters. Similarly to traditional clusters, cultural clusters enjoy numerous agglomeration advantages just for the sake of sharing specialized infrastructure, a common labor market, transfer of knowledge, luring the same target groups or common marketing. Cultural clusters have become one useful instruments for the regeneration of diverse urban areas [4]. 
Arguably, it is not necessary to provide a reminder that specific and peculiar cultures are typical for old industrial territories. This is doubly valid in contemporary post-transformation economies, in which their pre-transformation legacies and institutions are still deeply embedded $[5,6]$.

The purpose of this article is to analyze and examine cultural and creative industries in Ostrava, the third largest town in the Czech Republic that at the same time embodies a typical representative of old industrial urban fabrics in the country. Special attention will be devoted to the emerging cultural clusters that constitute a useful tool for the revitalization of various urban areas. Cultural clusters appear to be indispensable in terms of sustainable cultural management.

From a methodical point of view, semi-structured interviews accomplished with relevant actors of a town's culture facilitated contextual interpretation of the role of cultural and creative industries as well as mapping and monitoring the potential cultural clusters in the town. The research question formulated for the purposes of our paper is as follows: do development effects shaped by the concentration of creative and cultural industries in Ostrava exist?

The added value of the article consists in mapping and monitoring the concentration of cultural and creative industries and subsequent interpretation of related effects in large post-industrial town in post-transformation country and uncovering the paths towards sustainability. In this case, external stimuli, i.e., loss in the contest for the title of the European capital of Culture enhanced positive internal endeavors aimed at the development of urban culture. Such a kind of vivification is typically not concomitant to traditional economic branches, however creative and cultural industries seem to be more elastic and resilient in this respect.

The debates on these currently vogue concepts in advanced and more affluent western economies often lead to their glorification and even labeling as cure-all-maladies. Yet, the situations in post-transformation economies differ substantially and uncritical adoption of these concepts without appropriate contextualization in the frame of post-transformation economic-societal settings could lead into the void. Thus, the need for such kind of studies is indisputable.

The structure of the manuscript is as follows: after the introduction, the literature review section follows. The paper then proceeds to its background as well as the materials and methods. Results are discussed widely from both quantitative and qualitative standpoints. Finally, the whole article culminates in the chapters focusing on the discussion and conclusions.

\section{Literature Review}

There are only minor doubts that the last few decades have witnessed the processes of economization and commodification of culture. However, the relation between the economy and culture is slightly more tricky to determine. For culture and cultural processes, non-standardized, spontaneous and often tacit characteristics are typical. In contrast, standardization is inherent to the economy as it expresses the economy's pragmatic and profit-oriented drive.

The cultural sector is not constrained by rational rules, which is its strength. Culture may positively influence an economy in the sense of finding new solutions and new approaches to currently pressing and difficult to solve socioeconomic issues. At the same time, the widely perceived culture represents a softening social and value fabric above the rationalized economy. That's why it is desirable that culture and economy influence themselves mutually. Hitherto, the economy puts the screws on the culture. In other words, culturalization of the economy that has been severely underrated should complement contemporary relations between the economic and cultural sectors $[7,8]$.

Creative industries and cultural industries form an inner fulfilment of the culture. Even more importantly, these industries can be intercepted from both quantitative and qualitative perspectives. It is generally accepted that their role within economies of various territorial ranks has an increasing tendency. While creative industries became a buzzword and to some extent a hazy notion, their subset, which is represented by cultural industries, enables a more intense focus that is useful from both theoretical and practical perspectives. Nonetheless, it has to be stated that there is nothing like a 
generally accepted definition of the cultural sector and cultural industries so far. Indeed, a certain elasticity is inherent to the culture.

Definitions of The United Nations Educational, Scientific and Cultural Organization (UNESCO) and the General Agreement on Tariffs and Trade (GATT) can be comprehended as a certain point of departure for the purposes of our article and according to them, cultural industries combine the creation, production, and distribution of goods and services that are cultural in nature and usually protected by intellectual property rights. The notion of cultural industries generally includes textual, music, television, and film production and publishing, as well as crafts and design. These are knowledge-based industries that create employment and a better institutional-social milieu, as well as other benefits.

In order to structure, differentiate and better grasp cultural industries, it is pertinent to use one of the following approaches [9]:

- Sectoral approach,

- Labor market and organization of production,

- Creative index.

A large number of issues concerning the cultural sector and cultural industries are related to the fact that cultural industries and cultural sector usually concern large metropolitan areas. What remains to be answered is the role of culture and cultural industries in other types of territories. Since this article focuses upon Ostrava, the third largest town in the Czech Republic in terms of population size, we also have to take into consideration rather specific attributes of traditional industrial areas, of which Ostrava is a typical representative.

The cultural sector and cultural industries underline the relevance of tacit knowledge and skills, creativity and talent of individual entities as well as their networks. The markets, in which these entities function, are of a highly competitive and volatile nature. Labor markets in cultural industries are strongly competitive too and a substantial part of employees is working part-time, which is in discordance with sustainability principles. Temporary projects are the most typical way of working in cultural industries. As for the size structure of firms involved in these projects, the vast majority of them are of a micro/small character and there are only a few large global players. The above characteristics in a way undermine the economic importance of culture. On the other hand, the flexibility of the culture complies with contemporary trends in the economy [10-12].

As already indicated, the cultural sector and cultural industries tend to develop in large metropolitan territories. It is generally accepted that the importance of hard location factors is stable or even declining as they became nearly ubiquitous in advanced leading economies. In contrast with that, soft location factors are getting increasingly relevant. Indeed, the atmosphere or image has become an essential element for the presence of the cultural sector in various localities, regions or whole states.

Large agglomeration economies, proximity to suppliers as well as to customers, specialized labor forces and/or access to information, which are typical signs of large metropolitan territories, act as a stimulus of a spatial concentration of creative and cultural industries $[13,14]$. These areas usually offer conditions that draw on the ideal state of a 'creative milieu'. Such a milieu is a physical setting where a critical amount of entrepreneurs, intellectuals, artists or administrators operate in an open-minded, cosmopolitan context and where face to face interactions shape new ideas, products, services and/or institutions [1-3].

In case that a critical mass of people in the given territory thinks and acts in a positive and territorially-conscious way, they form the spaces of harmony existing at the intersection of natural territorial characteristics and preferences of the population inhabiting the territory in question. A critical mass of people always has 'a contagious effect' on the rest of the community in the given territory and pulls previously undecided individuals in their direction. In our case this involves positive and cultural thinking and acting consciously in relation to the inhabited territory. 
From a wider perspective, we are entitled to talk about the mutual exchange of positive energy between the people and their environment. This synergy stems from the fact that a territorially bound population behaves consciously and positively towards the surrounding environment while taking into account its genius loci. In that way, truly cultural and creative spaces can be formed [7].

At the same time, one should consider that previously depicted positive characteristics can be found only in a very limited number of territories so far. Typically, their affluence from an economic perspective is eloquent. As for traditional industrial towns in post-transformation countries, this harmonic state is barely imaginable as people strive primarily for the satisfaction of economic needs and there is also low level of trust in the society [7].

One cannot ignore the fact that conceptions concerning the cultural sector and industries were born in advanced and wealthier economies in the West. It is thus only hardly surprising that their applications reckon with standard Western economic-institutional environments. Nonetheless, history matters and economic-institutional environments in Central and Eastern Europe are rather distant from their Western peers as they still bear heavy economic-institutional burdens of the past. Moreover, experience shows that return to the natural developmental track without a deformed economic-institutional milieu usually takes two or three generations $[5,6]$. This naturally raises many queries about the applicability of a cultural sector and cultural industries in post-transformation countries and territories. Naturally, one size hardly fits all.

The research gap is twofold in our case and our paper attempts to contribute to filling in these gaps. First, from methodical and methodological perspectives-as already suggested-creative and cultural industries play different roles in mature Western and post-transformation economies. This holds true with even higher intensity for traditional industrial areas that have their own peculiar cultures. In case of post-transformation countries, spontaneous rather than programmatic development takes place and endogenously developing creative and cultural industries based on inner potential of territorially-bound population seem to be more untamed and resilient. Nonetheless, their contemporary role and weight in Central East Europe cannot be overestimated.

Second, in the Czech Republic as well as other Central East European countries, the data on creative and cultural industries are far from perfect. They suffer from a high degree of fragmentation, incompleteness as well as inadequate time series (if there are any at all). That is why, the analysis of their composition and development, which is in our case also enriched by qualitative research, contributes to the partial filling of the large empirical gaps.

A substantial role in drawing on the sustainability of cultural management in our context is played by clusters. There are plenty of different definitions of the term cluster, which is a seminal notion with regards to this article. According to reference [15], there is no clear definition of a cluster since clusters differ in individual regions or sectors and it is therefore more appropriate to consider the definition only as a cover concept rather than as a precisely defined term.

In the research, the term cluster is frequently confused with the term cluster initiative. Cluster initiatives are organized endeavors aimed at augmenting the growth and competitiveness of clusters in the region with the participation of the cluster companies, the governments and/or the research communities [16].

A rather frequented delimitation of the cluster was introduced by reference [17], which defines it as follows: 'a geographically close group of interconnected companies and affiliated institutions in a particular area whose common feature is complementarity in certain areas.' Clusters are 'dominating the landscape of every advanced economy, as its emergence is an essential part of economic development and offer a new way of thinking about the economy and economic development' [18]. An important attribute of well-functioning clusters is their sustainability.

For the purposes of our article, we concentrate on cultural clusters. Similarly to the above mentioned traditional clusters, cultural clusters benefit from ample agglomeration advantages just due to the sharing the specialized infrastructure, common labor market, transfer of knowledge, luring the 
similar or same target groups or common marketing activities. Cultural clusters became one useful instruments for the vivification of various types of mainly urban areas.

Cultural clusters can be narrowly delimitated-a typical form is a museum or theater cluster; nonetheless cultural clusters can be multifunctional as well and can offer a diverse group of artistic activities, such as music, design or the others. Cultural clusters often underline various forms of social leisure or entertainment, such as cafés, bars, sport and social infrastructure. In that way, synergic effects are being augmented. Cultural clusters are useful tools for cultural managements.

As reference [4] points out, there are a great variety of spatial forms of cultural clusters. Projects may restrict themselves to standalone buildings or they may include entire quarters or building complexes. Mostly, the projects are housed in former industrial complexes, but rather frequently they also entail the building of new sites.

\section{Background}

Old industrial towns and cities are territories that experienced their strongest growth in the period of industrialization. Hence these territories came to be known as centers of heavy industry, i.e., metallurgy or mining. In some cases, their industrial monoculture was based on the textile industry. Chaotic and spontaneous settlement and population growth is a typical sign of these areas. From the geographical point of view, these spatial entities typically form large urban agglomerations or conurbations.

The rise of traditional industries drove the growth of these urban areas. However, it ultimately became the bane of their development, since it distorted the orientation of their economies. Currently, a lot of these urban entities are forced to cope with a distinct shrinkage from both population and economic perspectives.

These spaces are also quite peculiar from the institutional perspective. Both their formal and informal institutional characteristics distinguish them substantially from other types of territories. The dominance of large enterprises forms a culture of dependency and weakens entrepreneurial activity. This is connected with the lack of an innovative milieu and a certain inertia of deeply embedded habits, particularly among industrial workers. On the other hand, positive features include a higher level of solidarity, responsibility, and technical and organizational discipline derived from hard work. Basically, peculiar culture is typical for this kind of areas and subsequently, cultural management bears a lot of specific features $[19,20]$.

For a long time, traditional industrial urban areas benefited from economic growth. However, the 1960s and 1970s proved to be turning-points in their history. Technological advances and the subsequent process of globalization revealed the vulnerability of their economies. Increased competition in the world markets connected with the move from a Fordist 'industrial economy' towards a post-Fordist 'information economy' imposed profound transformation in these territories [7,20].

There is little doubt that the decay of old industrial areas in Central and Eastern Europe differs substantially from that of their Western counterparts in terms of both the origin and the nature of their troubles. The specific legacy of socialism, which can be expressed as a complex and interconnected social, economic and environmental deformations, is hampering the transformation of these urban areas severely [7].

Ostrava, which is the focus of the article, represents a multicultural urban entity with a complex and inconsistent development. Moreover, Ostrava's peculiarity is further enriched by the town's traditional industrial character. Ostrava's characteristics are strongly linked with the town's location in Central Europe. Numerous issues connected with this intriguing Central European region go beyond the extent of this article; however, it should be stated that, as defined by Milan Kundera, this area was 'geographically in the Center, culturally in the West, and politically in the East'. Ostrava's growth trajectory was thus shaped by an enormously complicated context that was very often aggravated by unfavorable political-administrative settings. 
The discovery of coal deposits in 1763 and the foundation of an ironworks in the neighboring small village of Vítkovice in 1828 embodied the beginning of Ostrava's massive development. This was further strengthened by the utilization of Ostrava's favorable geographical location: the town was located just in the middle of the Vienna-Krakow railway line that was built in 1847. Industrialization transformed a town of artisans and agrarians into an industrial metropolis. This substantially affected the mode of settlement, the construction of facilities as well as the composition of the population. Ostrava's architecture nowadays reflects the heritage of the past: valuable Art Nouveau or functionalistic complexes persist alongside industrial architecture.

The development of industry in connection with the accumulation of the capital stimulated the construction of public facilities and brought numerous remarkable edifices. From the cultural point of view, the town was transformed into a multicultural center, as its wide offer of jobs in all categories acted as magnet for people from all corners of the Austro-Hungarian Empire. This marked the foundations of Ostrava's peculiar culture, which is dissimilar to other towns in the Czech Republic.

In spite of its significance, Ostrava has never been a favorite town of Czechoslovak/Czech governments. The town was compelled to deserve its existence and to fight for it. Hence, Ostrava's administrative and political importance was practically always qualitatively one step behind its importance in terms of industry and population. Ostrava's industrial vigor before World War II was largely constrained by its inadequate political-administrative context [20,21].

Ostrava, formerly called the 'Steel Heart of Czechoslovakia' is the typical example of the victim of communistic industrial megalomania. Rough industrial growth resulted in the low-level image of the town that was known as an environmentally and socially unpleasant place inhabited by rude people. From a spatial standpoint, low permeability of the borders and a subsequent lack of both material and intangible communications caused the general retardation of practically all Socialist countries. Not surprisingly, Ostrava as a frontier town was hit rather severely by this semi-autarky as former Czechoslovakia was one of the most diligent pupils of the Soviet system. In 1989, Ostrava's agglomeration provided some $86 \%$ of Czechoslovak coal mining, $82 \%$ of coke production and $70 \%$ of steel production. Approximately $52 \%$ of inhabitants worked in the secondary economic sector, $7 \%$ in the primary sector and a mere $41 \%$ in the tertiary sector $[20,21]$.

After the Velvet Revolution in 1989, the country underwent the double transformation consisting of the move from a totalitarian to a pluralistic democratic political system and from a centrally planned economy to a market economy. These processes were further enriched by general modernization tendencies briefly expressible as a shift from Fordism towards post-Fordism. These frame conditions substantially delimitated Ostrava's course of transformation. The situation was complicated by Ostrava's inadequate socioeconomic structure stemming from its industrial past that turned out to be vulnerable under new socioeconomic circumstances.

Thus, it is far from surprising that the position of the town on mental maps remains an unsatisfactory one. In spite of a gradual transformation of all principal urban socioeconomic structures and a rising quality of life, Ostrava and its surroundings are still perceived as a territory of heavy industry, socio-pathological phenomena and other negatives. This bad image is often compounded by the media coverage at the national level.

As a consequence of that, Ostrava is currently a rather inconspicuous place from the tourism point of view. But this is in sharp discordance with the fact that the town previously acted as a business, economic and cultural center. The architecture and the memory of the town represent valuable witnesses of this history. So, contemporary Ostrava lies in the middle of Central Europe but at the same time is at its periphery. Conflicts can be perceived as inseparable parts of the town's development that symbolically resembles the sine curve [20,21].

Nowadays, as a consequence of the long-term influence of the communistic regime, Ostrava is still returning to the natural developmental track and is looking for its new mission and identity. A bad position on mental maps combined with little maneuvering space for self-government meant that there is only a little room for the town's genuine endogenous development. Yet, it should be 
noted that contemporary Ostrava's population size is almost 300,000 inhabitants and the town forms a natural socioeconomic center of agglomeration with nearly 1 million inhabitants. This naturally creates sufficient space for markets of all kinds, including a cultural one.

In 2009 Ostrava's management decided to compete for the prestigious title of European Capital of Culture and to take part in contest with another Czech town: Pilsen. The competing town of Pilsen enjoys a good geographical location in between the Czech capital city of Prague and Germany. The town was less beset by industrialization in the past and enjoys larger economic diversity. However, with a smaller population of some 170,000 inhabitants, the cultural infrastructure of the town is not extraordinary.

The most distinguishing feature of Ostrava 's project aiming at the title of European Capital of Culture 2015 was unprecedented integration of the traditional Ostrava image into the project and its communication. The entire project activated many actors of Ostrava's culture and helped to create an atmosphere of collaboration boosted by positive expectations related to Ostrava's supposed victory in that contest.

Even former president Václav Havel supported Ostrava in its candidacy. The project website [22] quoting his speech from the Ostrava candidacy clip provides his words: 'Ostrava, always too far from the capital, has created its unique genius loci, which is basically relying just on itself. As almost a synonymous to Ostrava are still heavy industry and coal mining rather than culture or education. Finally the drawbacks from the past deliver new hopes to revitalize the places, which resisted attempts of social engineering, collectivization or globalization pressures. Thus I am happy and endorse the candidacy of the City of Ostrava for the title of European culture capital 2015 as a commitment to recognize, appreciate and expand the beauty of Czech landscape and cities which is not to be recognized at a first sight. However I am sure, that more Czech cities would like to stand for the title of European culture capital and maybe they would deserve it, I appreciate Ostrava at most to be the choice.'

In 2010, Pilsen was announced as the European Capital of Culture 2015. Naturally, this brought large disenchantment to Ostrava. At the same time, since the town's DNA is permeated by the consciousness of self-reliance, it seems that the failure in the competition for the European Capital of Culture indeed brought several benefits. These benefits can be seen by monitoring the cultural and creative industries in the town, via deepening public consciousness on Ostrava's culture towards identification of potential cultural clusters in the town. Important actors of Ostrava's culture agreed that in spite of the loss, Ostrava remains a cultural town. Empirical evidence shows that despite the financial loss as a consequence of the failure in the competition for the European Capital of Culture, we are witnessing the development of Ostrava's culture.

\section{Materials and Methods}

Spatially-orientated research usually tackles both quantitative and qualitative perspectives. A fine blend of both of these perspectives enables us to identify the most relevant aspects of examined elements and phenomena. In our case, we also utilized both quantitative and qualitative methods, but preference was given to the latter because of the lack of quantitative data on the one hand and possibility of contextual interpretation of information found out during the interviews on the other [23].

It has to be noted that cultural industries represent a rather new concept in the Czech Republic. Shortcomings or more precisely misunderstandings that abound in the theoretical sphere are moreover accompanied by a low quality of collected data as well as insufficient statistical resources. Thus, there appeared numerous limitations and constraints related to the quantitative components of the article. We are still unable to create any longer time series and consequently, spatial developmental tendencies related to cultural industries can be only barely evaluated.

Not surprisingly, the quantitative dimension of the paper will be much more modest than its qualitative counterpart. Yet, limited quantitative data are available based on secondary information from the Czech Register of Economic Entities and Czech Statistical Office. This allows us to intercept at least roughly the geographical distribution of cultural and creative industries in the country. 
For the purposes of our study, we applied pragmatic sector delimitation of creative and cultural industries [24,25].

In order to gather relevant qualitative information, we utilized semi-structured interviews. In contrast to structured interviews, this meant we could collect more interesting and contextually chosen information. Moreover, we were still able to compare the answers in a satisfactory manner. Non-structured interviews can be barely compared and that is why a semi-structured version turned out to be useful for our purposes and enabled not only comparison of the information gathered but also their basic classification.

Subjective evaluations of interviewees are typical for the answers we gained. But since creative and cultural industries are relatively new and in a way are not-yet-established conceptions, the high degree of creativity and spontaneity in answers could be detected. Altogether 10 interviews were completed. Interviewees included various groups, such as artists, public administration employees, marketing experts, teachers and others.

What these interviewees had in common was working in Ostrava, dealing with cultural issues in Ostrava and basic knowledge of art and urban developments issues. Taking into account a pretty constrained time framework of the vast majority of interviewees, at the beginning, they were contacted by e-mail and in case of no response they were then contacted via telephone. After the clarification of the purpose of the research they were visited. The interviews comprised just 9 open questions.

The contents of semi-structured interviews covered various aspects of Ostrava's cultural life. Individual questions revolved around important topics starting from the character of cultural and creative industries via their impact on local employment towards the emerging cultural clusters in the town's landscape. Sufficient attention was also devoted to strengths and weaknesses of Ostrava's candidacy for a title of European Capital of Culture in 2015 in relation to Pilsen, the competitor that finally won the contest and got that prestigious title.

Although the qualitative part of the research was not flawless (e.g., in terms of the subjectivity of the answers), it still represents an appropriate and valuable complement to the quantitative part of our research.

\section{Results}

Culture is an inseparable part of current Ostrava's life. Its foundations are even stronger than in evolutionary developing towns as Ostrava's culture was always rather peculiar. As already mentioned in chapter 3, the town was compelled to fight for its existence, which was far from easy. Ostrava was always forced to deserve its position just due to its industrial character that was not accompanied by a corresponding position within the urban political-administrative hierarchy.

Contemporary Ostrava attracts visitors because of its cultural institutions and cultural events. The extra-regional reach of these institutions and events is confirmed by the fact that $35 \%$ of visitors do not come directly from Ostrava [25]. The town hosts ten theaters, eleven museums, tens of galleries, tens of libraries, ten cinemas, two multiplexes as well as regional TV and radio studios [26].

Over the year, Ostrava hosts plenty of musical events of various genres. These events include Janacek's May and St. Wenceslas Music Festival, as well as annual international festivals devoted primarily to classical music. Ostrava days represent a bi-annual festival concentrating upon contemporary classical music. In the summer, there are several well-known festivals, such as multi-genre festival Colors of Ostrava or Beats for Love, an electronic music festival. Janacek Philharmonic Orchestra is one of the most pronounced symphonic ensembles in the whole country.

In order to capture Ostrava's culture in a more appropriate and structured way, it is useful to distinguish quantitative and qualitative perspectives.

\subsection{Quantitative Perspective}

As for the quantitative-geographical view on Ostrava's creative and cultural industries, the position of the town should correspond to its place within the urban hierarchy of the Czech Republic. Yet, one 
cannot get rid of the town's industrial past so easily. This is palpable mainly in view of the fact that Ostrava's sector structure is rather distant to that of Prague (the capital city) and Brno (the second largest town in the country).

In concrete terms, Prague (population 1.2 million) itself accounts for nearly $40 \%$ of the country's jobs in the cultural and creative industries. The position of Brno (population 370000 ) is rather favorable too, as town's creative and cultural industries provided $9 \%$ of all working opportunities in the country. Ostrava, the third largest town in the country and with a population size that is close to Brno, provided just $3 \%$ of jobs in these industries in the country [27]. So, from the national perspective, Ostrava's position is by no means spectacular.

From regional perspective, the position of the town looks much brighter. Ostrava can be perceived as an indubitable center of the whole Moravian-Silesian region not only from a wider administrative and socio-economic perspective, but also from the point of view of creative and cultural industries. Ostrava's population reaches one fourth of the total population in the Moravian-Silesian region. Nonetheless, Ostrava comprises $52 \%$ of companies specializing in cultural and creative industries. The share of all other towns in the region is under $10 \%$ [25].

There are two important areas in Ostrava itself, where we can find a strong concentration of creative and cultural industries: the town center and the Mariánské Hory quarter. Spatial concentration of cultural industries in these two parts of Ostrava is in discordance with a rather negligible share of creative and cultural industries in other parts of the town as well as the rest of the Moravian-Silesian region. While in case of Ostrava center this can be attributed to the natural attractiveness of the area, in case of Mariánské Hory, the concentration of creative and cultural industries can be accounted for by a large concentration of entrepreneurs as well as the active approach of the local town hall managing the ward.

There are altogether 599 enterprises focusing on creative and cultural industries in the town center. Thus, the town center includes $43 \%$ of these industries in Ostrava and accounts for nearly $22 \%$ of these industries in the whole Moravian-Silesian region. Subsequently, we can contemplate a strong spatial concentration of creative and cultural industries in the Ostrava town center. Since a lot of these enterprises are mainly audience oriented, good accessibility plays therefore a significant role, which is also the case for the Ostrava town center [26].

From synthetic point of view, there is still room for the improvement of Ostrava's weight at the national level. Naturally, it is impossible to unload the burden of an industrial past in the short run. However, in terms of the culture-as well as from socioeconomic and administrative-political point of view-Ostrava is a clear Moravian-Silesian regional leader.

\subsection{Qualitative Perspective}

This part of the article contains the results of accomplished interviews that are shown mostly in a synthetic manner. Spatial concentration of companies in cultural industries shows that companies in these sectors tend to concentrate into the Ostrava town center. However, the concentration of cultural industries does not tell us anything about the quality of institutional milieu and co-operation among individual entities involved in the cultural industry. From the qualitative-geographical point of view, on the basis of gathered interviews, numerous interesting facts were disclosed.

The majority of interviewees agreed that we can speak of several cultural clusters in Ostrava. These clusters were identified as follows:

- Stodolní street-'Stodolní phenomenon' is what local residents and visitors have called one of the most interesting streets in Ostrava. The street has previously honorable town houses that decayed between the 1970s and 1980s. The dilapidated and dowdy street attracted the young and artists as local rents were some of the lowest in the whole Ostrava agglomeration in the 1990s, after the fall of the Iron Curtain. Today, there are over 100 clubs, restaurants and discotheques in and around Stodolní street. Whether clubbing, dining, listening to concerts or lectures, or meeting with artists 
at various exhibitions, there is always something to do on the 'Street that never sleeps'. The most intense nights out take place on Fridays and at weekends [28].

- A specific micro-cluster composed of Fiducia gallery with its program as well as two joint galleries.

- A network of cultural houses throughout the town located in different quarters that concentrate on educational, entertaining and cultural activities.

- Lower Vítkovice-since 2002 the site is a National cultural heritage site. The site represents a uniquely preserved flow of materials from coal mining to coke-plant and iron production. In 1998 its operations ended, but the site has survived. The Lower Vítkovice Iron Mills with the Hlubina Mine, Landek Mining Museum and the Vrbice Shaft are on the waiting list for registration as a UNESCO cultural heritage site. In August 2007 the Lower Vítkovice was opened to the public.

As stated by reference [26]: 'The importance of Lower Vítkovice, a national cultural monument, far exceeds the city, region and the Czech Republic. By reconstructing the original gas holder, the "Gong", a multinational congress center with a capacity of 1509 seats and its own gallery space, was created. The reconstruction of the original historical energy distribution station (U6) gave rise to the Small World of Technology, an interactive museum with educative elements. In September 2014, the Big World of Technology was opened in a completely new building. On an area of 14,000 square meters, visitors can discover four worlds-the Children's World, the World of Science and Discovery, the World of Civilization and the World of Nature. Since May 2015, Lower Vítkovice has a new landmark-the Bolt Tower (named after famous athlete). Standing almost seventy-eight meters high, the glazed superstructure of the Blast Furnace No. 1 serves as a lookout tower with multifunctional areas and a café.' The congress center as well as both the Small and Big World of Technology nowadays also form the most important concentration of cultural industry in the whole Moravian-Silesian region.

It is also worth mentioning the Black Meadow cultural cluster, which represents a unique opportunity for the whole region. Developing this cluster is possible only because of the specific historical settlement development in Ostrava. The relatively sparse urban structure of the town nowadays offers the chance to build up and improve the spatial qualities of Ostrava. There are not many other European towns offering the possibility to create an extensive urban-architectural project in such an exceptional location. The Black Meadow site is situated in a handy location just a few meters from Ostrava's main square.

Since the University of Ostrava managed to obtain over 1 billion of CZK from European funds, the project of educational area with two faculties can be launched. While one of them will host sport and new technologies, the other one will concentrate on art and design. The whole project that is arguably able to entice further positive culture-related activities into the whole area is supported by the Ostrava urban authorities.

Generally speaking, developmental potential of creative and cultural industries in Ostrava exists but is not yet utilized in an optimal way. Moreover, creative and cultural industries can be perceived as one of pivotal themes for the redefinition of urban functions of Ostrava in the future. Persons that were interviewed generally saw a great potential for the future of creative and cultural industries in Ostrava. Only two interviewed people were critical in that respect.

Cultural and creative industries can surely improve not only the image of Ostrava, which is far from optimal so far, but can also stimulate local human resources and provide them with new opportunities. Taking into account the truly high amount of talented people with large capabilities and tacit knowledge that live in the area, 'brain drain' tendencies can be mitigated by means of the promotion of cultural and creative industries and cultural and creative clusters in Ostrava.

Eighty percent of interviewed individuals were also convinced that creative and cultural industries and clusters have a positive influence on the labor market in the agglomeration and can contribute to the local employment. In contrast, the remaining twenty percent stressed the problem of temporary projects representing a typical form of employment in creative and cultural industries as well as the fact that genuine culture is basically of an elite nature and that is why it has only a negligible impact on local employment. 
According to the optimists, creativity, culture and mainly creative cultural clusters contribute not only to the formation of new working opportunities but also stimulate the production with high added value. Certainly, innovations constitute the corner-stone of creativity, culture and creative and cultural industries.

The biggest effect of the concentration as well as certain interactivity of creative and cultural industries in Ostrava can be seen in the formation of the so-called 'Growth Triangle'. This triangle consists of the already depicted Stodolní street, Lower Vítkovice and prepared Black Meadow cultural cluster. This territory is located basically in the town center. Moreover, distances are small enough for pedestrians, which facilitates shaping the room for a creative milieu.

In the gravity center of this 'Growth Triangle' we can find New Karolina site, which contains mixed functions, however, it includes also creative and cultural industries. New Karolina in Ostrava is one of the largest urban development and revitalization projects in the Czech Republic. Its entire area should cover 32 ha. The first of 4 planned phases comprises 57,000 sqm of shopping and leisure centers, an office building covering 23,000 sqm, a residential building with approximately 200 apartments as well as two historic buildings reconstructed to fulfill contemporary functions. With a total investment of over $€ 200$ million, the first stage has been already completed.

As stated by reference [29] 'The Nová Karolina development is planned to grow in consequent phases on the total site of 32 ha/79 acres, extending the historic city center towards the south and aiming at linking with Lower Vitkovice industrial heritage site and Black Meadow to the East. The estimated total $240,000 \mathrm{sqm}$ of mixed-function development will provide retail $(86,000 \mathrm{sqm})$, residential areas (1200 flats), offices (60,000 sqm), as well as spaces for leisure, entertainment and sport (12,000 sqm), all supported by ample parking areas, large green areas and complementary functions split proportionally in each phase.'

Naturally, the 'Growth Triangle' in Ostrava has both pros and cons. According to the accomplished interviews, strengths and opportunities are as follows:

- Multifunctional utilization of public spaces.

- Unique territory in the middle of large agglomeration.

- Interconnection of urban industrial history, entertainment at Stodolní street and a new cultural cluster can act as a bait for tourists.

- Accumulation of cultural activities where people involved in culture can generate new ideas and products.

- Concentration of entities with high added value.

- Creation of new working opportunities and new amenities for leisure and entertainment.

- Possible improvement of the image of the whole Ostrava agglomeration.

- In contrast, there are the following weaknesses and threats related to the formation of the 'Growth Triangle':

- Augmentation of uniform shopping areas.

- Possible liquidation of the urban historical core for the sake of new shopping opportunities in New Karolina.

- A possible lack of cultural events at Stodolní street, such as discussions, concerts, etc.

- The specific character of Stodolní street can hamper the natural integration of these places.

Put succinctly, some developmental effects evoked by the concentration of creative and cultural industries and creative and cultural clusters in Ostrava agglomeration can be identified, nonetheless, genuine qualitative transformation towards a more creative and cultural milieu in Ostrava and surrounding region is undoubtedly the question of longer time.

\section{Discussion}

The role of culture in advanced and post-transformation countries differs. While Western towns and cities are generally aware of both pros and cons of the culture and this category is firmly 
incorporated in their developmental strategies, their Central and Eastern European counterparts are often forced to undergo a rather painful trial-and-error approach. Moreover, Western towns and cities entered the next stage of a regeneration-through-culture agenda when we see a shift from a policy aimed at organizing occasions for spectacular consumption, to a more fine-tuned policy. This is directed to creating spaces, quarters and milieus for cultural production and creativity [4].

Before the detailed discussion, one should be aware of limitations of our research from both quantitative and qualitative standpoints. These limitations and constraints are thoroughly depicted in the subchapter named 'Materials and Methods' and concern mostly the low quality of collected data as well as a certain infancy of statistical resources from a quantitative point of view and subjective and possibly biased stances of interviewees from the qualitative perspective.

Cultural development in various parts of Ostrava has taken a different form in different places. Emergence of the phenomenon of Stodolní street in the 1990s can be contemplated as almost haphazard play of market forces when neither territorial nor functional regulations of the area were effective. However, after a certain time, we witnessed a distinct move from artist-led regeneration via property-led regeneration towards consumption-led regeneration. This development is in accordance with existing conceptions in this realm [30,31].

The case of Black Meadow is a different one. A planned cultural cluster can be seen as one of benefits of the unsuccessful competition to be the European capital of culture. The town always played an active role as Black Meadow was treated as an area of opportunity. Recently, the town transferred the whole site to the University of Ostrava in the form of a gift. The university tackled the Black Meadow cultural cluster project rather vigorously. Materialization of the whole project should commence in the middle of 2019. The synergy with the region is embodied also by the regional architects involved in the whole project.

The next corner of the 'Growth Triangle' is represented by Lower Vítkovice area. Its truly successful development can be attributed to the strong leadership in connection with patriotism of the owner [21]. Lower Vitkovice nowadays is the third most visited tourist attraction in the whole Czech Republic.

Last, but not least, in the gravity center of the above depicted 'Growth Triangle', we can find a New Karolína. This can be treated as quite successful project led by the external interests of developers residing out of Ostrava. Architectural qualities of the complex in combination with an excessive commercial function have been criticized many times, nonetheless culture-orientated components of the area are unquestionable. They are embodied by finely renovated historical objects where various concerts as well as other cultural events take place regularly.

On the basis of the analysis performed in the frame of this text, the answer to the research question formulated at the beginning of the paper is as follows: yes, development effects invoked by the existence of creative and cultural industries in Ostrava exist and help not only the diversification of the economy but overall regeneration of urban life as well. At the same time, it should be reminded that the development of these industries is slower than in other towns not beset by an industrial past. The great advantage Ostrava has is that it acts as the metropolis of the whole Moravian-Silesian self-governing region.

As to the managerial implications for practical policies, it should be reminded that genuine development in urban spaces can be reached primarily via the stimulation of inner endogenous potential of these urban entities [32]. Exogenous interventions cannot be entirely eliminated but they should act just as a complement to the endogenous activities of towns and cities. Development that is established on inner and truly endogenous regional potential is both effective and efficient because in contrast to exogenous strategy, it changes the quality of social and economic structures of individual territories.

At the same time, endogenous development (or combination of exogenous and endogenous development) can be successfully carried out only in the framework of adequately organized system 
macrostructures. Spatial distribution of these macrostructures should enable at least roughly just and homogeneous conditions for the development of individual territories [7].

As for the benefit for decision and policy makers, the study identifies the developments in the field of cultural and creative industries, which have been generally underestimated in old industrial areas. This is an even trickier issue in case of old industrial towns in post-transformation economies, where Ostrava belongs. A quantitative view is furthermore enriched by qualitative data that enhance formulations of particular recommendations.

Culture is an important component of life, but it cannot work properly if a place or an area in question finds themselves in a bad position on mental maps. That is why there should be sufficient space for marketing activities of urban areas emphasizing mainly positive elements and phenomena of their lives. This would help to lure more tourists, investors, students as well as other interesting target groups that would promote local cultural industries. This has even higher relevance for traditional industrial areas, among which Ostrava can be included.

One has to take into consideration the importance of public spaces that are indispensable for the formation of genuine culture. If we create and manage public spaces of any urban area, the collaboration of many experts from different fields is necessary. Only in that way we can reach the adequate emotional and functional synergy in the formation of public spaces. Urban settings should be planned by architects, economists, sociologists, psychologists, geographers and culturologists. Subsequently, we can draw on the improvement of outer aesthetics of urban spaces and people will be willing and glad to spend longer time at public spaces. This forms a positive milieu for further advancement of culture and cultural industries. This is the next important recommendation.

Local authorities should be also aware of the fact that more actors (including international ones) in the cultural industry means more co-operation as well as competition, along with the subsequent introduction of new ideas and products. That is why both domestic and international individuals and entities that are involved in cultural industries should be attracted to Ostrava. The town should reckon with the openness principle as a premise of success not only in the sphere of cultural industries and cultural clusters.

The above recommendations can help to the transformation of inner characteristics of the locals and desirable result of the whole process would culminate not only in the support of cultural industry and cultural clusters but also in everyday cultural behavior and cultural perceptions of life in general. Since informal institutions are usually changing in the long run, the tangible positive results cannot be obtained immediately.

\section{Conclusions}

Ostrava represents a traditional industrial town, which however finds itself in a post-transformation stage of its development. The role of the culture in the town is markedly different than that in advanced towns. In contrast to its Western counterparts, culture is not yet established as an integral component of Ostrava's development agenda and strategy.

There exists a distinct concentration of creative and culture industries in the territory occupied by Ostrava. Nonetheless, their importance is dependent upon the geographical context in which we assess them. While from the national perspective the position of Ostrava is in terms of cultural and creative industries quite a modest one, the town is undoubtedly a leader in the Moravian-Silesian self-governing region. This mirrors the fact that creative and cultural industries from Ostrava did not commence from scratch. At the same time, it should be remembered that the concentration of cultural and creative industries tells us nothing about the quality of these industries and the surrounding milieu as such. That is why in the frame of this article, a qualitative research has found ample utilization.

As it turned out, we can discuss the growth of a so-called 'Growth Triangle' consisting of Stodolní street, Lower Vítkovice, Black Meadow and Nová Karolina occupying the gravity center of this triangle.

The developments of each of these areas constitute specific stories. Stodolní street, which initially evolved into a cultural ward, sui generis, is moving towards being an entertainment zone nowadays. 
This street, where neither territorial nor functional regulations shaped the development in the 1990s, was created on the basis of free market forces. Nowadays, its prevailing commercial character is symptomatic for the whole area.

In contrast, the Black Meadow cultural cluster represents an intended endeavor of the urban authorities. The last developments show promising ground for the completion of a cultural cluster there. In contrast to Stodolní street, regulations virtually embrace the planned cultural cluster and two pivotal actors-urban management and the University of Ostrava-are currently participating in this project.

The case of Lower Vitkovice is perhaps the most connected with the failure of the candidacy to the European Capital of Culture. This failure only strengthened the strong endogenous basis of the whole project. The endogenous bias of the project was based on strong leadership in connection with sound patriotism.

Finally, New Karolína project, which finds itself just in the gravity center of 'the Growth Triangle', represents a fine blend of commercial and cultural functions. Culture surely contributes to Ostrava's overall regeneration, yet the question of the formation of cultural behavior in the town and cultural perception of life remains part of the long-distance goal.

In sum, development effects formed by the concentration of cultural and creative industries in Ostrava are distinctive. The failure in the competition for the European Capital of Culture fortified the endogenous character of the development of Ostrava's culture. This endogenous development without relying upon external resources is almost an inbuilt mechanism stemming from the town's complicated history.

As to the future possible tendencies in the research related to this topic, one should mention more intense co-ordination of individual endogenous activities that forms one of biggest challenges for Ostrava's future sustainable cultural management. The next issue concerns the question whether Ostrava's culture will be still capable of developing in an endogenous way, or whether some new patterns of development could emerge. Last but not least, transformation in the composition of Ostrava's cultural and creative industries towards a higher degree of progressivism could occur, which should be also subjected to further investigations.

Acknowledgments: This paper was supported within Operational Programme Education for Competitiveness-Project No. CZ.1.07/2.3.00/20.0296 and SGS project SP2019/46.

Conflicts of Interest: The author declares no conflict of interest. The founding sponsors had no role in the design of the study; in the collection, analyses, or interpretation of data; in the writing of the manuscript, and in the decision to publish the results.

\section{References}

1. Landry, C. The Creative City: A Toolkit for Urban Innovators; Earthscan Publication: London, UK, 2000.

2. Florida, R. The Rise of the Creative Class and How It Is Transforming Work, Leisure, Communication and Everyday Life; Basis Books: New York, NY, USA, 2002.

3. Florida, R. Cities and the Creative Class; Routledge: New York, NY, USA, 2005.

4. Mommaas, H. Cultural clusters and the post-industrial city: Towards the remapping of urban cultural policy. Urban Stud. 2004, 41, 507-532. [CrossRef]

5. Suchacek, J. Regional Development in Central and Eastern Europe: A New Approach. Actual Probl. Econ. 2014, 154, 106-115.

6. Suchacek, J. Large Enterprise Branches: The Case of the Czech Republic. Econ. Sociol. 2015, 8, 82-93. [CrossRef] [PubMed]

7. Suchacek, J. Territorial Development Reconsidered; VŠB-TU: Ostrava, Czech Republic, 2008.

8. Wróblewski, L.; Kurowska-Pysz, J.; Dacko-Pikiewicz, Z. Polish-Czech microprojects as a tool for shaping consumer behavior on the cross-border market for cultural services. In Innovation Management and Education Excellencce through Vision 2020; International Business Information Management Association: Milan, Italy, 2018. 
9. Gibson, C.; Kong, L. Cultural Economy: A critical review. Prog. Hum. Geogr. 2005, 29, 541-561. [CrossRef]

10. Scott, A.J. Creative cities: Conceptual issues and policy questions. J. Urban Aff. 2006, 28, 1-17. [CrossRef]

11. Pratt, A.C.; Jeffcut, P. Managing Creativity in the Cultural Industries. Creat. Innov. Manag. 2002, 11, $225-233$.

12. Grodach, C.; Seman, M. The cultural economy in recession: Examining the US experience. Cities 2013, 33, 15-28. [CrossRef]

13. Scott, A.J. The Cultural Economy of Cities. Essays on the Geography of Image-Producing Industries; Sage: London, UK, 2000.

14. Hutton, T.A. Spatiality, built form, and creative industry development in the inner city. Environ. Plan. A 2006, 38, 181-184. [CrossRef]

15. Pavelková, D. Klastry a Jejich Vliv na Výkonnost Firem; Grada: Prague, Czech Republic, 2009.

16. Sölvel, O.; Lindquist, G.; Ketels, C. The Cluster Initiative Greenbook; Ivory Tower: Stockholm, Sweden, 2003.

17. Porter, M.E. The Competitive Advantage of Nations; The Free Press: New York, NY, USA, 1990.

18. Porter, M.E. On Competition; Harvard Business School Press: New York, NY, USA, 1998.

19. Suchacek, J. Ostrava in the Context of Geopolitical Transformations: The Embodiment of Inconsistent Urban Development. Int. Cult. Cent. Yrly. 2007, 15, 53-58.

20. Suchacek, J. Na Cestě k Nové Identitě. Ostrava, Katovice a Košice Po Roce 1989; VŠB-TU: Ostrava, Czech Republic, 2010.

21. Suchacek, J.; Herot, P. The City of Ostrava_From Industrial Image to Industrial Image 2.0. In Harnessing Place Branding Through Cultural Entrepreneurship; Go, F., Lemmetyinen, A., Hakala, U., Eds.; Palgrave Macmillan: Basingstoke, UK, 2015; pp. 191-210.

22. Ostrava 2015 Candidacy for European Capital of Culture. 2015. Available online: http://www.ostrava2015. cz/web/structure/project-ostrava-2015-150.html?lang=en (accessed on 25 October 2018).

23. Caves, R. Creative Industries: Contracts between Art and Commerce; Harvard University Press: Cambridge, MA, USA, 2000.

24. The European Cluster Observatory Priority Sector Report: Creative and Cultural Industries. 2011. Available online: http://www.clusterobservatory.eu/common/galleries/downloads/CreativeAndCulturalIndustries.pdf (accessed on 5 October 2018).

25. Koncepce Rozvoje Kultury Statutárního Města Ostravy Včetně Aktualizace Akčního Plánu; Mimeo: Ostrava, Czech Republic, 2014.

26. Fact Sheets Ostrava 2017. City of Ostrava-Facts and Figures. 2018. Available online: https://www.ostrava. cz/en/podnikatel-investor/city-profile/ke-stazeni/ke-stazeni-en/copy_of_FL_2017_EN.pdf (accessed on 25 October 2018).

27. Slach, O.; Koutský, J.; Novotný, J.; Ženka, J. Creative Industries in The Czech Republic: A Spatial Perspective. E M Econ. Manag. 2013, 16, 14-29.

28. Stodolní Ulice. Available online: http://www.ostravainfo.cz/en/visit/the-best-of-ostrava (accessed on 25 October 2018).

29. Nová Karolina. Available online: http://www.nova-karolina.cz/clanky/nove-karolina-project (accessed on 25 October 2018).

30. Cameron, S.; Coaffee, J. Art, gentrification and regeneration: From artist as pioneer to public arts. Eur. J. Hous. Policy 2005, 5, 39-58. [CrossRef]

31. Slach, O.; Boruta, T. What can cultural and creative industries do for urban development: Three stories from the post-socialist industrial city of Ostrava. Quaest. Geogr. 2012, 31, 99-112. [CrossRef]

32. Castanho, R.A.; Naranjo Gómez, J.M.; Kurowska-Pysz, J. How to Reach the Eurocities? A Retrospective Review of the Evolution Dynamics of Urban Planning and Management on the Iberian Peninsula Territories. Sustainability 2019, 11, 602. [CrossRef]

(C) 2019 by the author. Licensee MDPI, Basel, Switzerland. This article is an open access article distributed under the terms and conditions of the Creative Commons Attribution (CC BY) license (http://creativecommons.org/licenses/by/4.0/). 